\title{
Ibuprofen in the current practice of the pharmacist in the community pharmacy
}

\author{
Paula ANTONOAEA ${ }^{1}$, Nicoleta TODORAN¹, Emőke RÉDAI ${ }^{1}$, Robert Alexandru VLAD ${ }^{1}$, \\ Magdalena BIRSAN ${ }^{2}$, Aura RUSU ${ }^{3}$, Adriana CIURBA ${ }^{1}$ \\ ${ }^{1}$ Faculty of Pharmacy, Department of Pharmaceutical Technology and Cosmetology, \\ University of Medicine, Pharmacy, Science and Technology "George Emil Palade", Targu Mures, Romania \\ ${ }^{2}$ Department of Pharmaceutical Technology, Faculty of Pharmacy, \\ "Grigore T. Popa" University of Medicine and Pharmacy, lasi, Romania \\ ${ }^{3}$ Department of Pharmaceutical Chemistry, Faculty of Pharmacy, \\ University of Medicine, Pharmacy, Science and Technology "George Emil Palade", Targu Mures, Romania
}

\begin{abstract}
The pharmacist from the community pharmacy plays a key role in the case of patients who seek directly for pathologies related to pain. Being a health specialist, he has the ability to offer pharmaceutical healthcare for drugs that need a medical prescription and also for the ones that are registered as OTC's. Ibuprofen (IBU) is a part of the drug group called nonsteroidal anti-inflammatory drugs (NSAIDs) being registered in Romania under 17 pharmaceutical formulation by the National Agency of Drugs and Medical Devices. Due to its pharmacological profile which consists of a low risk of gastrointestinal side effects, IBU is an OTC recommended and frequently prescribed for decreasing the low and moderate pain. World Health Organization (WHO) indicates IBU as a drug that can be used to babies aged over three months. Through this paper, we try to analyze the pharmacist's vision from the community pharmacy in IBU recommendation. In this paper were mentioned some legal aspects that are linked to the pharmacist competences, and also its approach regarding $I B U$ recommendation during pregnancy and breastfeeding and also to children and to a category of patients who have various associated pathologies.
\end{abstract}

Keywords: ibuprofen, pharmacist recommendations, OTC, pain

\section{INTRODUCTION}

Millions of people take the threshold of a pharmacy to get their medications available with or without prescription for pain associated pathologies. In civilized countries, people give great attention to self-care under their knowledge, to the information found via the internet in conjunction with the recommendations of a healthcare specialist. This study aims to approach the pharmacist point of view from the community pharmacy as a specialist in healthcare in the ibuprofen recommendation in some painrelated conditions.
PHARMACEUTICAL HEALTHCARE - LEGAL ASPECTS

In Romania, the pharmacist profession is exerted under Law 95/2006 and one of the activities provided in Article 568-point $g$ ) is referring to providing information and counseling the patient 
regarding the drugs prescribed and their appropriate use. Taking into consideration the law mentioned above the pharmacist is defined in Article 903-point $f$ ) as a health professional. The pharmacist can offer pharmaceutical healthcare, a fact that implies giving the correct information to the patient regarding the posology, duration of the treatment, some contraindications and cautions including the provision of information regarding the association with beverages and food [1].

PAIN THERAPY PHARMACIST APPROACH A THEORETICAL PERSPECTIVE

The patients that are confronting with different pathologies manifested through pain are addressed many times directly to the pharmacist. Due to its skills, the pharmacist has expertise in pain therapy management and the inflammatory processes. Many patients who present those pathologies do not reach in the first instance to the doctor and prefer to request the pharmacist's advice. By the competences that the pharmacist has, he is perceived by the patients as a specialist of the healthcare capable to offer the fair treatment [2].

The pain is defined by the "International Association for the Study of Pain" IASP as a sensorial and emotional disagreeable experience, given by a potential veritable tissue fluid lesion or a description with terms referring to such lesion [3]. The pain causes are various: injuries, pressure and traction on the nociceptors in case of muscular contractions, vasoconstriction, distensions of the viscera, tumors. Three levels of pain are known for which the specialty literature recommends some medication as a function of the pain severity:

- easy pain: in which paracetamol or anti-inflammatory drugs (NSAIDs) are recommended;

- moderate pain: in which combinations of opioids with paracetamol or NSAIDs are recommended;

- severe pain: in which opioids are recommended given by various administration ways suitable for the patient [4].

Depending on the evolution, pain can be acute or chronic. Acute pain represents a symptom in the case of a disease considered as an important alarm system for the body protection. It responds to a usual antalgic therapy and does not give any physical or mental disease. The chronic pain can persist for six months, and it is often resistant to the usual antalgic therapy. This type of pain can continue even after healing of a primary painful lesion due to the pain reaching the central system, remaining thereby in the "head of the patient" [3-6].

There is a varied number of pharmaceutical products used for pain therapy, many of them offered to the patient as OTCs (Over the Counter), which means that they do not require a prescription to be released from the pharmacy [7].

The patients usually come in the pharmacy to request from the pharmacist a product known, but on many occasions they ask pharmaceutical care regarding their pathology. In both cases, the pharmacist plays a key role in choosing the product designed for 
pain therapy. On many occasions the pharmacist represents the last chain of the health medical system. However, when he must give medications upon request it is recommended to perform a short anamnesis of the patient regarding the other pathologies known or other medication used chronically. He has to obtain enough information to recommend an optimal treatment in his health issue with which the patient is coming to the pharmacy. Thus, possible interactions can be avoided between the medicine prescribed and the treatment already used. By its easy accessibility, the pharmacist from the community pharmacy is the one that will offer professional counseling, will establish the posology of the recommended drug and the duration of the treatment. The easy pain therapy includes using NSAIDs, and it is usually the first recommendation of the pharmacist. By its skills, the pharmacist can make recommendations in moderate and severe pain when he can give as an adjuvant an NSAID and can direct the patient to a doctor to prescribe an opioid [8].

\section{NSAIDs are substances whose} mechanism of action implies the reduction of prostaglandin biosynthesis by blocking $\operatorname{COX}_{1}$ and $\mathrm{COX}_{2}$ reversible. From the two isoforms of the COX enzyme, $\operatorname{COX}_{1}$ is constitutively occurring in all the tissues. It occurs in endoperoxide synthesis with beneficial, protective, properties: $\mathrm{PGI}_{2}$ prostacyclin (antithrombotic, anti-sclerotic and cytoprotective); $\mathrm{TxA}_{2}$ and $\mathrm{TxB}_{2}$ (favors platelet aggregation); prostaglandins $\mathrm{PGE}_{2}$ (bronchodilators, gastric cytoprotective and natriuretic). As a result, it can be said that $\mathrm{COX}_{1}$ inhibition determines a side effects mechanism generator. $\mathrm{COX}_{2}$ is a constitutive isoform only in some tissues such as lungs, kidneys, spinal cord. In the presence of some extern proinflammatory stimuli (macrophage, other cells) $\mathrm{COX}_{2}$ becomes inducible in all the tissues, and it is involved in the prostaglandins biosynthesis with inflammatory role found in the peripheral level and medullary: $\mathrm{PGF}_{2}, \mathrm{PGF}_{1 \alpha^{\prime}} \mathrm{PGE}_{1}$. As a result, blocking this isoform of cyclooxygenase explains the anti-inflammatory mechanism of action [9-12].

\section{Ibuprofen (IBU) is an NSAID from} the first generation, recommended in the acute pain. It is the first compound from this group approved for over the counter recommendation. From a structural point of view, this molecule was the first discovered in 1960. It has been seen as an alternative to acetylsalicylic acid. Developing IBU as a drug was patented in 1961 by Dr. Adams Stewart Sanders and the organic chemist, Nicholson John Stuart (patent number 971700) $[14,15]$. It is marketed since 1969 in the United Kingdom and since 1974 in the United States of America. Chemically it is a propionic acid derivative. IBU is a racemic mixture $1: 1 \mathrm{R}(-): \mathrm{S}(+)$, the anti-inflammatory and analgesic action being owed to the $\mathrm{S}(+)$ enantiomer. It is absorbed fast orally, its bioavailability being over $80 \%$. It has a half time of $2-2.5$ hours, being fast metabolized in the liver, while the renal excretion is the most important way of elimination [14]. From a pharmacotoxicological point of view in the case of IBU, the digestive disorders which can occur via the mechanism of action have a lower frequency compared to acetylsalicylic acid which includes it 
in the category of NSAIDs with the lowest gastrointestinal risk, information confirmed by the actual research. The results published by Varassi et al. in 2020 have highlighted the fact that IBU is a NSAID with the safest pharmacological profile [16]. A study conducted on 8677 patients based on following the side effect of three OTCs (paracetamol, IBU and acetylsalicylic acid) proved that between paracetamol administered in doses of $3 \mathrm{~g} /$ day and IBU administered in doses of $1.2 \mathrm{~g} /$ day small differences were noticed. Instead, compared with acetylsalicylic acid administered in doses of a maximum $3 \mathrm{~g} /$ day fewer side effects were reported in the case of IBU. [9,13-18].

Taking into consideration the data presented in Table 1, IBU is authorized in Romania by National Agency of Drugs and Medical Devices (ANMDM) under 17 pharmaceutical formulations, being recommended starting from three months of age [19].
Even though IBU is in most of the cases classified as an OTC, the pharmacist must provide great attention to the potential interactions with other active pharmaceutical ingredients. Some examples of possible interactions which might take place are: in the case of patients treated with an oral anticoagulant (warfarin) which increases the gastrointestinal bleed risk; in the case of diabetic patients who are using oral antidiabetic drugs - it increases the hypoglycemia risk, in the case of patients found under treatment with Angiotensin-Converting Enzyme Inhibitors - the blood pressure is increasing and, the renal function might be worsening.

\section{THE PHARMACIST ROLE IN IBU USE IN PREGNANCY AND BREASTFEEDING}

Special attention must be given to pregnant and breastfeeding women $[19,20]$. There are five risk categories approved by the Food \&

TABLE 1. Pharmaceutical forms with IBU authorized by ANMDM

\begin{tabular}{|c|l|c|c|}
\hline Nr. crt. & Pharmaceutical form & Concentration & $\begin{array}{c}\text { Nr. of the IBU brand } \\
\text { names authorized in } \\
\text { Romania }\end{array}$ \\
\hline 1. & film-coated tablets & $200 ; 400 ; 600 \mathrm{mg}$ & 11 \\
\hline 2. & sugar coated tablets & $200 ; 400 \mathrm{mg}$ & 6 \\
\hline 3. & sustained-release tablets & $800 \mathrm{mg}$ & 1 \\
\hline 4. & prolonged-release capsule & $300 \mathrm{mg}$ & 1 \\
\hline 5. & liquid capsules & $200 ; 400 \mathrm{mg}$ & 4 \\
\hline 6. & hard capsules & $200 ; 400 \mathrm{mg}$ & 4 \\
\hline 7. & soft chewable capsules & $100 \mathrm{mg}$ & 1 \\
\hline 8. & medicated plaster & $200 \mathrm{mg}$ & 1 \\
\hline 9. & suppository & $60 ; 125 \mathrm{mg}$ & 1 \\
\hline 10. & solution for injection & $5 \mathrm{mg} / \mathrm{ml}$ & 1 \\
\hline 11. & solution for infusion & $200 ; 400 ; 600 \mathrm{mg}$ & 8 \\
\hline 12. & oral suspensions & $100 ; 200 \mathrm{mg} / 5 \mathrm{ml}$ & 2 \\
\hline 13. & oral powder & $200 ; 400 \mathrm{mg}$ & 1 \\
\hline 14. & granules for oral solution & $400 ; 600 \mathrm{mg}$ & 2 \\
\hline 15. & envelopes oral suspension & $200 ; 400 \mathrm{mg}$ & 5 \\
\hline 16. & gel & $50 \mathrm{mg} / \mathrm{g}$ & 1 \\
\hline 17. & cream & $50 \mathrm{mg} / \mathrm{g}$ & \\
\hline & & & \\
\hline
\end{tabular}


Drug Administration (FDA) in the case of using medicines in pregnancy: A; B; C; D; X [22]. It is very important that the pharmacist ask women-patients of a possible pregnancy. IBU is an NSAID included in many risk categories depending on the moment of exposure. FDA includes IBU in the B category (studies carried out on animals did not demonstrate a fetal risk) for the first and second trimester of pregnancy while for the third one IBU is included in the $C$ category (it can produce fetal risk) [23]. The potential risk of the third trimester is associated with the closing of the arterial channel. Due to the acid character, IBU binds on the plasmatic proteins, and it is ionized in a high percentage at plasmatic $\mathrm{pH}$. These properties confer IBU to be fitted in the drugs category compatible with breastfeeding, the passage in the human milk being very low $[20,23]$.

\section{THE PHARMACIST KEY ROLE IN RECOMMENDATION OF IBU IN PEDIATRICS}

It is well known that the children usually get the flu or develop respiratory diseases more often than adults. The main cause referred is immunity, which is developed during the years. Thus, the susceptibility and the kid's behavior to touch their nose, mouth, and also the objects determine that the immune system is triggering an answer to the viruses with which comes into contact. Many times, the treatment is a nonpharmacological one, but for the improvement of the symptoms caused by the pain or fever, OTC medications are used. World Health Organization (WHO) published a list "World Health Organization. Model List of Essential Medicines, 21st List 2019" in which the main medicine is sure and effectively used in the case of children with a maximum age of 12 years, between them IBU being nominated. [24] Following WHO specifications, IBU can be administered just in the case of babies with age higher than three months in the treatment of pain. To newborns, it is administered in special cases and only intravenously, in order to close the arterial channel. As a result of the pharmacological predictable pharmacologic profile, the pharmacist as a specialist in healthcare, recommends IBU to kids for easy to moderate pain such as headache, toothache, throat ache and, earache and also in febrile episodes belonging to colds and also after vaccination [24-26].

\section{CONCLUSIONS}

Following the presented data, we can conclude that IBU is one of the surest NSAIDs prescribed and recommended by the specialist in healthcare. Taking into consideration the in-force legislation and including the scientific data presented, the pharmacist by its competences recommends as a unique treatment or as an adjuvant treatment to patients with symptomatology manifested by pain, an NSAID, in most of the cases IBU, especially taking into consideration the lower risk regarding the side effects.

Conflict of interest: none declared Financial support: none declared 


\section{REFERENCES}

1. Law 95/2006, Practicing the profession of pharmacist, available at https://www.anm. ro/dispozitive-medicale/legislatie/ legi-ordonante-si-hotarari-de-guvern/ (accessed on September 14, 2020).

2. Netere AK et al. Assessment of community pharmacy professionals' knowledge and counseling skills achievement towards headache management: a cross-sectional and simulated-client based mixed study. The Journal of Headache and Pain. 2018; 19:96. https://doi.org/10.1186/s10194-018-0930-7.

3. https://www.iasp-pain.org/ PublicationsNews/NewsDetail. aspx?ItemNumber $=10475$ (accessed on September 14, 2020).

4. Wells BG, Schwinghammer TL, DiPiro JT, DiPiro CV. Manual de farmacoterapie, $10^{\text {th }}$ Edition. Bucuresti: Editura Prior, 2019.

5. Hamood R et al. Chronic pain and other symptoms among breast cancer survivors: prevalence, predictors, and effects on quality of life. Breast Cancer Res Treat. 2018;167:157-169.

6. Treede RD et al. Chronic pain as a symptom or a disease: the IASP Classification of Chronic Pain for the International Classification of Diseases (ICD-11). Pain. 2019;160(1):19-27.

7. Perrot $\mathrm{S}$ et al. Self-medication in pain management: The state of the art of pharmacists' role for optimal Over-TheCounter analgesic use. Eur J Pain. 2019; 23:1747-1762.

8. Wee Tan AC, Lynne Emmerton L. Nonprescription medicines: current issues in Australian community pharmacy. IJPP. 2009:17:207-213.
9. Motov S et al. Comparison of Oral Ibuprofen at Three Single Dose Regimens for Treating Acute Pain in the Emergency Department: A Randomized Controlled Trial. Ann Emerg Med. 2019;74(4):530-537.

10. Bindu $S$ et al. Non-steroidal antiinflammatory drugs (NSAIDs) and organ damage: A current perspective. BCP. 2020; 180:114147.

11. Varrassi $G$ et al. The Expanding Role of the COX Inhibitor/Opioid Receptor Agonist Combination in the Management of Pain. Drugs. 2020.

12. Gritsenko K. Nonsteroidal Antiinflammatory Drugs (NSAIDs). In: Khelemsky Y, Gritsenko AMK. Academic Pain Medicine. A Practical Guide to Rotations, Fellowship, and Beyond. Switzerland: Springer, 2019:69-73.

13. Finkel R, Clark MA, Cubeddu LX et al. Lippincott's Illustrated Reviews: Pharmacology, $4^{\text {th }}$ Editon. Florida: Lippincott Williams\&Wilkins, 2009.

14. https://www.drugbank.ca/drugs/DB01050 (accessed on September 3, 2020)

15. Halford GM et al. $50^{\text {th }}$ anniversary of the discovery of ibuprofen: An interview with $\mathrm{Dr}$ Stewart Adams. Platelets. 2012;23(6):415422.

16. https://www.ema.europa.eu/en/medicines/ human/paediatric-investigation-plans/ ibuprofen-paracetamol (accessed on September 17, 2020)

17. Varrassi $G$ et al. Ibuprofen Safety at the Golden Anniversary: Are all NSAIDs the Same? A Narrative ReviewAdv Ther (2020) 37:61-82.
18. Moore N, Pollack C, Butkerait P. Adverse drug reactions and drug-drug interactions with over-thecounter NSAIDs. Ther Clin Risk Managem. 2015;15(11):1061-1075.

19. https://www.anm.ro/nomenclator/ medicamente?dci=ibuprofen (accessed on September 14, 2020).

20. Vari C, Dogaru T. Medicamentul, sarcina și alăptarea. Targu Mures: Editura University Press, 2007.

21. Albassam A, Awad A. Community pharmacists' services for women during pregnancy and breast feeding in Kuwait: a cross-sectional study. BMJ Open. 2018; 8:e018980.

22. https://www.fda.gov/drugs/labelinginformation-drug-products/pregnancy-andlactation-labeling-drugs-final-rule (accessed on September 24, 2020)

23. https://www.drugs.com/pregnancy/ ibuprofen.html (accessed on September 2020).

24. 21st WHO Model List of Essential Medicines (2019), available at https://apps.who.int/ iris/bitstream/handle/10665/325771/ WHO-MVP-EMP-IAU-2019.06-eng.pdf?ua=1 (accessed on September 2020).

25. Maguire TA. Ibuprofen: a model medicine for self-care of common conditions. Int J Clin Pract. 2013;67(178):43-46.

26. Hindi AMK et al. Solidarity or dissonance? A systematic review of pharmacist and GP views on community pharmacy services in the UK. Health Soc Care Community. 2019; 27:565-598. 